\title{
LAPORAN SUKA-DUKA PENEMUAN PRASASTI RAJA JAYAPANGUS DI KROBOKAN DAN BENDA PURBA LAINNYA DI SEPANG (BALI)
}

\section{Oleh: M. M. Sukarto K. Atmodjo}

Setelah kami kembali dari Tugas Belajar Utama di Rijks-Universiteit Leiden (1968-1969), pada suatu hari Dekan Fakultas Sastra UNUD (Universitas Udayana) di Denpasar minta kepada kami agar bersedia menyertai rombongan mahasiswa jurusan Anthropologi UNUD yang akan melakukan penelitian dialek bahasa di Sepang, Perbekelan Sepang, Kecamatan Busungbiyu, Kabupaten Buleleng. Hal ini berdasarkan berita (sinyalemen) bahwa penduduk setempat masih menyimpan beberapa buah benda purbakala. Permintaan itu kami sambut dengan baik, dengan pengharapan mudah-mudahan di daerah sekitar Sepang juga ditemukan sarkofag, mengingat palungan (sarkofag) tersebut pernah ditemukan di Busungbiyu, Pujungan dan di Pohasém. 1

Demikianlah pada tanggal 26 Oktober 1969 jam 4 malam kami berangkat dari Kantor Wilayah Purbakala II Bedaulu (Gianyar) dengan sepeda kumbang menuju Denpasar. ${ }^{2}$ Tepat jam 5 menjelang pagi rombongan yang terdiri dari 35 orang Dosen dan mahasiswa berangkat menuju Sepang.

Jurusan Anthropologi di bawah pimpinan Sdr. Drs. I Gusti Ngurah Bagus (sekarang, Dr) dan rombongan purbakala kami pimpin sendiri dan terdiri daribeberapa orang. Ikut serta dalam rombongan tersebut Sdr. Drs: Moh. Amir Sutaarga, Kepala Direktorat Museum Pusat di Jakarta waktu itu.

Rombongan menggunakan bis sewaan dengan arah perjalanan Denpasar - Pulukan - Asahduren - Bunutbolong --Dapdappatih (waktu berangkat) dan Pupuan - Pujungan - Antosari - Denpasar (waktu pulang). Sewaktu rombongan berhenti sejenak di Pulukan melepeskan lelah, seorang mahasiswa Fakultas Hukum UNUD (Sdr. Koti Santika) mengatakan bahwã di rumahnya masih tersimpan beberapa lembar prasasti dan mengharap agar kami bermalam untuk membaca pada keesukan harinya. Karena sebetulnya Kantor Wilayah Purbakala II sedang menerima rombongan tamu mahasiswa jurusan Bahasa Inggris dari GAMA (Gadjah Mada), maka kami mengusulkan apakah mungkin dibaca pada hari itu juga. Setelah dipikir masak-masak, mahasiswa tersebut mengatakan: "Baiklah akan kami usahakan". 
Setelah berhenti sejenak bis segera meluncur meninggalkan Pulukan melalui Asahduren ${ }^{3}$ menuju ke Dapdapputih. Dari Dapdapputih rombongan melanjutkan perjalanan dengan berjálan kaki dan dipecah menjadi dua rombongan. Sebagian kecil berjumlah enam orang langsung menuju desa Krobokan tempat penyimpanan prasasti (Perbekelan Sepang, Kacamatan Busungbiyu). Rombongan kecil ini terdiri dari: Sdr. M.M. Sukarto K. Atmodjo sebagai pimpinan, Sdr. Drs. Moh. Amir Sutaarga, Sdr. Sayu (mahasiswi Anthropologi), Sdr. Koti Santika (mahasiswa Hukum) dan dua orang mahasiswa jurusan Purbakala (Arkeologi). Rombongan besar lainnya terdiri dari duapuluh-sembilan orang di bawah pimpinan Sdr. Drs. I Gusti Ngurah Bagus langsung menuju ke desa Sepang. Karena waktu itu telah menunjukkan jam 11 siang, maka kami berjanji setelah melakukan penelitian selama kirakira dua jam segera akan menyusul ke Sepang dan diharapkan pada jam empat sore, yaitu tepat pada waktu diturunkannya benda-benda suci purbakala dari dalam pẽlinggihnya, ${ }^{4}$ rombongan kami sudah akan tiba di sana. Waktu itu kami tidak menduga akan menemukan prasasti kuna tersebut, karena kerapkali kami menerima berita yang sama tetapi ternyata hanya prasasti lontar belaka (prasasti klas tiga). ${ }^{5}$

Setelah berjalan kira-kira setengah jam dari jalan besar menuruni tebing jurang, sampailah kami di rumah Sdr. Pan Koti (clan warga Santika). Sdr. Koti Santika sendiri kemudian menjelaskan kepada ayahnya maksud kedatangan rombongan. Sesudah itu barulah disusul upacara keagamaan di depan pẽlinggih Saka Pat Sari tempat menyimpan piagam. Sementara itu rombongan yang akan bertugas membaca mengenakan pakaian adat Bali. Kedua belah tangan kami, juga dari teman-teman lainnya dicuci dengan air tirta (air suci) sebagai pertanda. bahwa rombongan kami telah bersih dari sifat-sifat letê̌h (kotor) dan bebas dari noda-noda dosa. Segera kami dipersilahkan duduk di atas kursi di halaman muka rumah dengan didampingi oleh teman-teman lainnya. Waktu itu matahari bersinar dengan teriknya membakar tubuh, meskipun gumpalan awan yang tebal menghitam mulai bergelimangan 'di sana sini. Setelah seorang dari warga Santika mengucapkan mantramantra gaib dan disusul kebaktian yang khidmat, prasasti dikeluarkan dari dalam pělinggih. Hati dan jantung kami berdebar-debar menantikan apakah prasasti tersebut kuna ataukah baru. Perlahan-lahan selubung kain putih yang sudah usang berbintik-bintik pembungkus prasasti dibuka oleh pemiliknya dengan hati-hati dan khidmat. Maka terpaparlah di hadapan kami beberapa lembar. prasasti tembaga. Hati kami melonjak berteriak karena gembira. Ucapan pertama yang terlontar dari mulut kami karena gerak refleks hanyalah "kuna". Terik ma- 
tahari tidak lagi terasa meskipun keringat mulai mengalir bercucuran di atas kening dan dahi kami.

Prasasti tersebut terdiri, dari enam lembar lempengan tembaga dengan huruf Jawa Kuna yang cukup jelas, meskipun di beberapa tempat tulisan agak kabur dan berkarat. Ukuran lempengan (pelat) prasasti rata-rata panjang $39 \mathrm{~cm}$ dan lebar $9 \mathrm{~cm}$. Nomer urutnya yaitu $1,2,4,5,6$ dan sebuah lagi tidak jelas nomernya karena telah patah menjadi dua dan hanya tinggal sebagian. Melihat bekasnya mungkin dipatahkan dengan sengaja, barangkali pada waktu warga mereka berpindah tempat dan piagam harus dibagi dua. Tulisan timbal balik di kedua belah sisi, kecuali pada lembar pertama. Setiap sisi digoresi dengan enam baris kalimat Jawa Kuna. Karena sempitnya waktu ( \pm 2 jam) dan tidak mungkin melakukan transkripsi selengkapnya, maka tindakan kami terlebih dahulu yaitu membuat rubbing ${ }^{6}$ dengan bantuan teman-teman lainnya. Betul-betul pada waktu itu kami semua tenggelam di dalam kesibukan yang menggembirakan. Tetapi rasa sedih dan dukalara menyayat hati kami karena tidak dapat memotret untuk keperluan dokumentasi. Satu-satunya kamera milik Kantor Wilayah Purbakala II kami tinggalkan di rumah, karena tidak dapat digunakan lagi dengan baik. Bagian alat yang paling vital, yaitu lensanya telah rusak. Maka dipandang perlu Wilayah Purbakala II dilengkapi dengan kamera dan peralatan lainnya. Di samping itu juga kendaraan.

Rasa sedih dan penyesalan yang tak terhingga ini terulang lagi di Pura Děsa Sepang karena kami tidak dapat memotret benda-benda sejarah purbakala yang tersimpan di sana. Aduhai! Kapankah kami dapat melakukan penelitian dengan perlengkapan yang lebih baik? Kapankah? Temuan benda-benda purbakala yang melimpah ruah di Bali dan di Nusa Tenggara menantikan tangan-tangan yang penuh kasih sayang dari purbakalawan dan purbakalawati kita dengan peralatan yang baik. Tentunya sebelum terlambat diambil para pedagang benda antik dan wisatawan yang membanjiri pulau Bali dan Lombok khususnya.

Sementara teman-teman lainnya sibuk membuat rubbing, kami mulai membersihkan lempengan pertama dengan kain putih. Dan dengan suara keras dan jelas kami baca kalimat-kalimat tersebut beserta terjemahan dan penjelasannya sebagai berikut:

1. //O//i saka 1103 srawanamasa, tithi nawami suklapaksa, ma, pa, bu, waraning wayangwayang, irikā diwaśa, ãjñ̂a păduka srì mahara- 
2. ja haji jayapangus arkajalancana, saha rajapatnidwaya paduka sri parameswari indujaketana, paduka sri mahädewi sasangkajacihna

3. umajar-i ya senapati, umingsor-i tanda rakryan ring pakirakiran-i jro makabehan, karuhun mpungku sewasogata, rèsi mahàbrahmah-

4. na, i pingsornyajnanira paduka sri maharaja, ajarĕn sira kabeh, sembandha mangrengo päduka śri maharaja, ri katidopayanikang karaman epu ka-

5. pgan tan wringdaya, alánala haleh mawicara lawan sang-admak-akmitan-apigajih, angken cetramasa, ya ta dumadyaken trasantasah manah di-

6. kang karaman jmur tan pahamngan, tan-atutur sumambut swakarmmanya ri swadesanya, makahetun-i tan paparyanta sakweh ni padrwyahajyanya, apan

Berarti lebih-kurang:

1. Pada tahun Saka $1103(1181 \mathrm{M}$ ) bulan Srawana (bulan Kasa = Juli-Agustus), tanggal 9 paro-terang, Mahulu; Pahing, hari Rebo, wuku Wayangwayang, pada waktu itu bersabdalah Paduka Sri Maharaja.

2. Haji Jayapangus Arkajalancana (yang bertanda keturunan matahari), ${ }^{7}$ bersama-sama dengan kedua orang permaisurinya, masing-masing bernama Paduka Sri Parameswari Indujaketana (yang bertanda keturunan bulan) ${ }^{8}$ dan Paduka Sri Mahadewi Sasangkajacihna (yang bertanda keturunan bulan), ${ }^{9}$

3. bersabdalah kepada Senapati, diturunkan kepada Tanda Rakryan ring Pakirakiran di dalam semuanya, terlebih dahulu (diutamakan) kepada pendeta Siwa dan Buddhà, para resi dan brahmana agung,

4. adapun perintah (ajna) yang diturunkan oleh Paduka Sri Maharaja, supaya diberitahukan kepada mereka semua, sebab Paduka Sri Maharaja mendengar tentang kegelisahan dan kesedihan penduduk desa,

5. susah tak tahu daya-upaya, berbicara tentang kebaikan dan keburukan (berselisih pendapat) dengan Sang-admak-akmitanapigajih (nama pejabat) setiap bulan Cetra (Kesanga = Maret April), sehingga menyebabkan ketakutan dan kesedihan hati. 
6. penduduk desa, hancur kering tak terlindungi dan tidak dapat melakukan tugas-kewajiban mereka masing-masing di desanya sendiri dan berakibat tidak teraturnya (?) penyelenggaraan (pemungutan) semua pajak negara (padrwyahaji), ${ }^{10}$ karena

Tiba-tiba setelah kami selesai membaca dan menjelaskan artinya kepada pemilik prasasti, bahwa yang mereka simpan adalah piagam raja Jayapangus yang telah berumur kira-kira 788 tahun (sampai dengan tahun $1969 \mathrm{M}$ ) dan boleh jadi ia merupakan pengganti raja Ragajaya, ${ }^{11}$ pemilik prasasti mendadak duduk dan menangis berkepanjangan dengan himbauan nada-nada naik-turun yang memilukan. Ia telah kerangsukan arwah leluhurnya, ia in trance. Segera dupa dibakar oleh anaknya dan asap yang tebal hitam memenuhi pĕlinggih serta tempat di sekitarnya, mantra-mantra diucapkan di depan Saka Pat Sari, tangan bersikap anjali (menyembah) memohon doa restu dari dewa betara. Sebentar kemudian pemilik prasasti sadar kembali, tepat pada waktu itu terik matahari berganti dengan hujan rintik-rintik. Semakin lama semakin deras. Kami bergegas-gegas masuk ke dalam rumah membawa prasasti untuk menyelesaikan pembuatan rubbing.

Setelah kami duduk, warga Santika menjelaskan kepada kami, bahwa prasasti tersebut telah disimpannya secara nami (turun-temurun) dan bahwa warga mereka sebetulnya berasal dari desa Sanding. Sejenak kami mulai membaca lempengan lainnya, meskipun waktu suđah sangat mendesak, karena penduduk Sepang telah menantikan rombongan kami untuk meneliti benda-benda purbakala yang mereka sungsung di dalam Pura. Tiba-tiba perhatian kami tercurah pada lempengan tak bernomer yang telah putus menjadi dua bagian, 12 karena lempengan itu menyebut nama karaman Buyan-Sanding-Tamblingan. ${ }^{13}$ Nama Buyan dan Tamblingan sekarang berubah menjadi nama dua buah danau di pedalaman pulau Bali dan terletak berdampingan (bersanding) sedangkan nama desa Sanding antara lain terletak di daerah Kabupaten Gianyar. Di Sanding Gianyar inilah kami pernah menemukan sebuah sarkofag dan gelang-gelang perunggu. ${ }^{14}$ Setelah mengetahui bahwa prasasti yang mereka simpan juga menyebut nama Saṇding (tempat asal warga Santika), mereka merasa lebih yakin dan hormat terhadap benda pusaka yang mereka simpan dan disungsung secara nami. Boleh jadi warga Santika tersebut memang keturunan langsung penduduk Buyan-Sanding-Tamblingan dari jaman raja Jayapangus.

Setelah selesai pembuatan rubbing, prasasti dibungkus kembali dengan hati-hati dan disimpan di dalam pëlinggih. Hidangan makan 
siang dan buah-buahan mulai disajikan. Karena kami telah lapar, segera hidangan tersebut kami serbu dengan lahapnya. Tepat pada jam 1,30 siang rombongan minta diri dari warga Santika dengan pengharapan dalam waktu dekat akan datang sekali lagi melakukan pembacaan ulang (rechecking).

Kami tinggalkan rumah mereka dengan rasa bangga dan gembira karena dapat menemukan prasasti, lebih-lebih dapat memberikan penjelasan. Keyakinan kami sewaktu masih berada di Nederland bahwa segera setelah pulang ke Bali pasti menemukan prasasti, sekarang telah terlaksana. Juga Sdr. Amir Sutaarga mengatakan setibanya nanti di Jakarta ákan segera melaporkan kepada Pak Soekmono tentang temuan baru tersebut.

Rombongan berjalan cepat menuju Sepang yang terletak nun jauh di sana, di lembah ngarai yang cukup dalam. Karena sukarnya perjalanan, Sdr. Sayù (mahasiswi) dan dua orang lainnya menantikan di jalan raya, di tempat bis. Meskipun kami telah berulang-kali menyusuri lembah dan bukit di pulau Bali, namun perjalanan waktu itu rasarasanya yang terberat. Sejauh $8 \mathrm{~km}$ team kami harus berjalan meluncur di tebing jurang yang cukup dalam dan menakutkan, kadang-kadang merangkak dan pada waktu pulang nanti $8 \mathrm{~km}$ lagi harus mendaki ke jalan raya. Hanyalah karena tugas dan kemauan keras serta ikatan janji dengan penduduk Sĕpang kami bergerak maju penuh keyakinan. Berkali-kali rombongan kami tergelincir di semak-semak belukar dan bangun kembali. Kami maju menerobos hutan kopi mengikuti jejakjejak kaki manusia. Selangkah demi selangkah, jatuh bangun berulangkali. Rasa-rasanya kami seperti Rajapala atau Raden Jaka Tarub yang sedang menjelajahi hutan belukar mencari telaga hening suci nirmala tempat para bidadari sedang mandi bersuka ria.

Selama $2 \frac{1}{2}$ jam rombongan berjalan letih lesu menuruni tebingtebing ngarai yang berliku-liku. Akhirnya setelah menyeberangi sungai Sepang yang. jernih bening airnya, desa yang kami harap-harapkan mulai kelihatan. Bahkan di sana sini tampak pula penduduk berpakaian adat aneka ragam membawa saji-sajian di atas kepala. Dari jauh sayup-sayup sampai kedengaran pula bunyi gamelan yang dapat menambah semangat kami, justru pada waktu kekuatan hampir punah. Sejenak team berhenti duduk di atas batu besar di tengah sungai yańg jernih. Angin pegunungan yang bertiup sejuk menambah kesegaran badan. Kami membasuh kaki dan tangan. Sentuhan air sungai Sëpang yang dingin terasa seperti air-penghidupan yang memberikan nafsu dan tenaga baru. Tenaga muda penuh semangat. Segera kami berganti ba- 
ju mengenakan pakaian adat, karena kedatangan team tersebut pasti disambut dengan meriah. Kàmi melangkah maju meneruskan perjalanan ke desa Sepang dengan langkah yang pasti dan mevakinkan, seperti keyakinan akan terbitnya matahari di hari esuk. Di belakang kemudian tergabung serombongan gadis-gadis ayu dengan senyumnya yàng manis. Senyum gadis pegunungan yang asli. Sederhana tetapi penuh gairah. Mereka memakai pakaian adat aneka warna serta menyunggi sajisajian atau pajegan di atas kepalanya. Maklumlah pada waktu itu seluruh penduduk sedang berpesta pora merayakan hari raya piodalan Pura Desa yang bertepatan pula dengan waktu purnamaning Kapat (purnama bulan ke empat). Desa Sépang semakin dekat dan bunyi gamelan semakin keras kedengarannya. Rombongan kami bertamban panjang dan berjalan satu-satu meliwati pematang sawah yang hanya cukup untuk berpapasan. Semua merasa gembira. Gelak ketawa bergema memantul kembali dari tebing-tebing ngarai yang tinggi. Team kami berjalan di barisan terdepan dan kemudian menyusul rombongan gadis-gadis ayu di belakang. Seakan-akan kami sebagai ksatriya-ksatriya yang baru pulang dari medan perang dengan membawa kemenangan serta memboyong putri domas (800 orang putri).

Seperempat jam kemudian sampailah kami di tengah-tengah kesibukan dan keramaian Pura. Kami bertemu kembali dengan Sdr. I Gusti Ngurah Bagus dan rombongan mahasiswa lainnya. Penelitian bahasa telah selesai mereka kerjakan. Kami dipersilahkan duduk dan sebentar kemudian hidangan mulai disajikan. Sambil menikmati makanan dan air kopi yang hangat sedap, kami tunjukkan hasil rubbing dan pembacaan prasasti di Krobokan. Mereka heran dan kagum mengapa tulisan yang sudah berabad-abad lamanya dan tidak mungkin dibaca oleh Pedanda atau pendeta di Bali, sekarang dapat dibaca dan diketahui isinya. "Itulah tugas purbakala", sahut kami.

Selesai menikmati hidangan segar di wantilan, ${ }^{15}$ seorang Pemangku Pura ${ }^{16}$ segera mempersilahkan kami dan dua orang mahasiswa lainnya masuk ke dalam jeroan (bagian dalam.Pura). Mantra-mantra suci diucapkan dan bergema memenuhi Pura dengan dibarengi suara genta yang bergemerincingan. Seakan-akan paduan suara yang gaib (magisch) itu membubung tinggi bersama-sama asap dupa yang dibakarnya. Semua penduduk, kecuali kami bertiga, jongkok di depan gedong (bangunan tertutup) dan pëlinggih (bangun terbuka) tempat menyimpan benda-benda keramat. Setelah itu seorang Pedanda memegang kedua belah tangan kami seraya memercikkan air suci berulangkali dan mengucapkan puji-pujian serta mantra gaib kepada Sang 
Hyang Iswara. Kata-kata yang kami tangkap antara lain mengatakan bahwa sekarang sudah tiba saatnya benda-benda suci yang mereka sungsung akan dijelaskan makna dan artinya oleh seorang purbakalawan, serta mohon doa restu dari dewa betara. Selesai pencuciaǹ tangan kami dari sifat-sifat lěttěh (kotor), segera kami menuju ke sebuah balai tempat benda-benda suci akan diturunkan. Penduduk mulai berjejaljejal jongkok di depan balai tersebut, laki-laki perempuan tua muda dengan pakaian adat yang sangat indah. Semua mata tertuju kepada kami. Rasa-rasanya kami menghadapi suatu ujian di tengah lapangan terbuka dengna disaksikan oleh ribuan khalayak ramai. Dalam batin. kami berdoa kepada Tuhan Allah dengan semangat Kristiani agar dapat memberikan penjelasan yang baik kepada seluruh masyarakat. Satu persatu benda suci dikeluarkan dengan hormat dan penuh khidmat. Karena kesuciannya hanyalah para pendeta dan kami saja dibenarkan menyentuhnya. Kami pegang benda-benda itu dan mulai memberikan penjelasan secarà ilmiah populer tentang arti, maksud, guna serta umurnya. Semua mendengarkan dengan tenang dan tertib, kadangkadang diselingi ucapan-ucapan "Beh, inggih, inggih, inggih" sebagai tanda setuju dan kagum. Sayang sekali kami tidak dapat memotret dan mengukur tinggi rendahnya benda-benda suci purbakala di atas. Ini disebabkan karena tidak adanya kamera, sempitnya waktu dan anggapan penduduk tentang kekeramatan barang-barang pusaka yang mereka sungsung.

Untuk jelasnya perincian benda-benda itu sebagai berikut:

1. Sebuah guci porselin buatan Cina dari sekitar abad XIV atau XV Masehi (kami telah berkonsultasi dengan ahli keramik dari museum Jakarta). Glasur berwarna putih coklat, dengan hiasan ular naga bersayap. Ukuran sebesar dua kali buah kelapa. Guci tersebut digunakan untuk menyimpan toya tirta (air suci).

2. Dua buah guci porselin Cina seperti tersebut di atas, tetapi lebih kecil bentuknya. Glasur mendekati warna coklat. Tanpa hiasan naga.

3. Sebuah lampu perunggu dengan hiasan sangka (siput) di bagian tengah atas. Menunjukkan sifat-sifat agama Wisnu (sekte Waişnawa). Melihat langgamnya kira-kira berasal dari jaman Majapahit.

4. Sebuah lampu perunggu dengan hiasan arca aśwa (kuda) di puncaknya. Mungkin dari sekte Waisnawa atau Saura (penyembah matahari). Kira-kira berasal dari jaman Majapahit.

5. Empat bilah keris luk dan lĕrĕs berasal kira-kira dari jaman kerajaan Gelgel atau Klungkung. 
6. Beberapa bilah gamelan perunggu (bilah gangsa).

7. Beberapa buah gong gede dan kempur (gong gantungan).

8. Sebuah alat musik (instrumen) menyerupai seruling yang disebut pleret. Bahan dari kayu dan bagian ujung ditambah dengan bulatan sehingga suara bertambah keras.

Selesai penelitian, benda-benda tersebut kemudian dikembalikan lagi ke dalam tempat penyimpanannya masing-masing. Dua diantaranya kami anggap penting ditinjąu dari segi purbakala, yaitu dua buah lampu gantung dengan hiasan sangka dan aśwa. Pada waktu itu jam telah menunjuk pukul 6 petang. Segera kami keluar dan bertemu kembali dengan rombongan Dosen dan mahasiswa di jaba pura (halaman luar Pura). Sebentar kemudian seluruh rombongan berpamitan dengan penduduk Sepang yang ramah tamah. Kami mengenakan lagi pakaian riset. Dengan diantar oleh empat orang penduduk yang membawa lampu petromax rombongan bergerak lambat-lambat mendaki lereng bukit menuju ke jalan besar. Rasa penat dan letih-lesu terulang kembali. Berkali-kali rombongan tergelincir dan jatuh-bangun. Bahkan seorang Dosen harus digandeng dan didorong oleh beberapa orang mahasiswa karena terjalnya pendakian. Rasa haus dan dahaga menyerang tenggorokan kami. Berkali-kali menanyakan kepada teman pemandu, apakah perjalanan masih jauh. Berulang kali mereka menjawab, setelah mendaki bukit itu sampailah di jalan besar. Namun bukit yang ditunjuk itu rasa-rasanya bergerak menjauhi kita. Tetapi akhirnya syukur alkhamdulilah. Setelah berjalan kira-kira 3 jam sampailah seluruh rombongan di tempat penantian bis dengan selamat. Segera kami menyerbu warung kopi di dekatnya dan sejenak bersendau-gurau dengan dagangnya (gadis penjual wedang) sambil minum kopi melepaskan lelah, haus dan dahaga.

Jam 10 malam bis bergerak meninggalkan Dapdapputih. Semua diam, tidak ada yang menyanyi atau bersiul seperti waktu berangkat. Bahkan beberapa orang kelihatan tidur bersandar di bahu teman di sampingnya. Semua merasa letih, kaki kejang-kejang, tetapi hati puas. Jam 12 tengah malam tibalah bis di kota Denpasar. Kami turun menuju museum bersama dengan Sdr. Moh. Amir Sutaargà. Karena kedatangan kami Sdr. Aburidho terbangun dari tidurnya. Setelah kami menikmati hidangan kopi malam yang hangat dan roti mentega di rumah Ibu Ni Made Kajĕng, kami meninggalkan kota Denpasar dengan mengendarai sepeda kumbang dinas yang kadang-kadang tokcer dan kadang-kadang tok-cet (macet). Sekali lagi perlu petugas purbakala dilengkapi kendaraan yang memungkinkan beroperasi cepat 
dan dapat berkejar-kejaran dengan pedagang benda antik serta memungkinkan pengusutan temuan-temuan benda purbakala secepat mungkin. Jam 2 malam sampailah kami di rumah, basah kuyup karena hujan deras di tengah perjalanan (di daerah Sukawati). Segera rubbing, yaitu satu-satünya dokumen yang dapat dibuat, kami ulang membacanya. Setelah jam 3 malam baru kami pergi ke tempat tidur dengan rasa bangga, karena perjalanan pada hari Minggu tersebut dapat dikatakan berhasil dan sukses. Sebelum tidur kami berdoa kepada Tuhan yang Mahakuasa dan kami kenang kembali Paduka Sri Maharaja Haji Jayapangus Arkajacihna yang mengaku keturunan matahari dengan kedua orang permaisurinya Paduka Sri Parameswari Indujaketana dan Paduka Sri Mahadewi Sasangkajacihna yang cantik jelita dan keduanya mengaku sebagai keturunan sang bulan. Alangkah serasinya perpaduan itu, putra matahari dan putri bulan. Akhirnya kamipun tertidur dengan nyenyaknya di dalam pelukan kedua orang putri bulan tersebut.

\section{Catatan.}

1. Karangan singkat berjudul "Penyelidikan makam purba di Pohasem" dimuat di dalam harian Suluh Marhaen (Edisi Denpasar), No. 225, Minggu tgl. 30 Mei 1965, hlm. I dan IV.

2. Sepeda kumbang tersebut mula-mula dipakai di Kantor Purbakala Prambanan, kemudian diserahkan kepada Sdr. Suharsono di Borobudur, selanjutnya digunakan di Kantor Purbakala di Mojokerto dan akhirnya karena budi-baik Sdr. Drs. A. S. Wibowo kemudian kami boyong ke Kantor Purbakala di Gianyar (Bali) untuk tugas sehari-hari sampai kira-kira tahun 1976).

3. Mengenai prasasti Asahduren lihat karangan M.M. Sukarto K. Atmodjo "Preliminary report on the copperplate inscription of Asahduren" di dalam BKI, deel 126, th. 1970, hlm. 215 - 227.

4. Yang dimaksud pelinggih yaitu bangunan di dalam Pura tempat menyimpan benda-benda suci (Purbakala) dan merupakan bangunan terbuka bagian depannya. Juga dianggap tempat linggih (duduk) para dewa-dewa.

5. Oleh almarhum Dr. R. Goris prasasti lontar (atau tembaga tipis) tersebut dianggap prasasti klas tiga, artinya isi kurang dapat dipercaya dan hanya menguraikan soal babad, pasek (semacam clan) dan cerita lainnya. 
6. Rubbing (dari to rub) berarti "gosokan". Yang dimaksud gosokan pensil di atas kertas yang ditempelkan pada prasasti tembaga atau perunggu.

7. Perkataan arka $=$ matahari, $\mathbf{j a}=$ keturunan, lahir, lancana $=$ tanda. Arkajalan̆cana = yang ditandai putra matahari.

Mengenai prasasti tersebut secara lengkap telah ditulis oleh M.M. Sukarto K. Atmodjo dengan judul 'Prasasti Buyan-Sanding-Tamblingan dari jaman raja Jayapangus", yaitu paper Seminar Sejarah Nasional II di Yogyakarta, tgl. 26 - 29 Agustus tahun 1970 (hlm. 1 - 52).

8. Perkataan indu = Saśangka $=$ bulan, cihna $=$ ketana $=$ lan̆cana = tanda. Indujaketana $=$ Saśangkajacihna $=$ yang ditandai menjadi putri bulan. Selanjutnya lihat M.M. Sukarto K. Atmodjo 'Prasasti Buyan-Sanding-Tamblingan dari jaman raja Jayapangus".

9. Lihat catatan No. 8 tersebut di atas.

10. Perkataan drwyahaji berarti "pajak raja", berasal dari drwya = milik dan haji = raja. Selanjutnya lihat M.M. Sukarto K. Atmodjo "Struktur masyarakat Jawa Kuna pada jaman Mataram Hindu dan Majapahit", diterbitkan oleh Pusat Penelitian dan Studi Pedesaan \& Kawasan Universitas Gadjah Mada, th. 1979, hlm. 57 - 64.

11. Lihat M.M. Sukarto K. Atmodjo "Struktur pemerintahan jaman raja Jayacakti”, di dalam majalah MISI, jilid VII, No. 2 1977, hlm. 35 - 54.

12. Separo bagian disimpan oleh keluarga Santika.

13. Perkataan karầman antara lain berarti: penduduk desa.

14. Lihat M.M. Sukarto K. Atmodjo 'Penggalian sarcophagus di Padangsigi (Sanding), di dalam harian Suluh Marhaen (Edisi Denpasar), Minggu tgl. 31 Desember 1967 dan Minggu tgl. 7 Januari 1968.

15. Bangunan besar di depan Pura (di bagian jaba) yang serba guna, artinya dapat digunakan untuk rapat, sabungan ayam dan tontonan lainnya. Berbentuk persegi (persegi panjang) tanpa dinding penutup. 


\section{DAFTAR BACAAN}

Sukarto K. Atmodjo, Martinus Maria

1967 Penyelidikan Makam Purba di Pohasem, di dalam harian Suluh Marhaen (Edisi Denpasar), No. 265, Minggu 4 Juni 1967, hlm. II.

1967 Penggalian Sarcophagus di Padangsigi (Sanding), di dalam harian Suluh Marhaen, Minggu tgl. 31 Desember 1967.

1968 Penggalian Sarcophagus di Padangsigi (Sanding), di dalam Suluh Marhaen, Minggu tgl. 7 Jảnuari 1968.

1970 Preliminary Report on the Copperplate Inscription of Asahduren, di dalam BKI (Bijdragen van het Koniklijk Instituut), deel 126, th. 1970, hlm. 215 - 227.

1970 Prasasti Buyan-Sanding-Tamblingan dari jaman raja Jayapangus, paper waktu Seminar Sejarah Nasional II di Yogyakarta, tgl. 26 - 29 Agustus th. 1970 (hlm. 1 - 52).

1977 Struktur Pemerintahan jaman raja Jayacakti, di dalam majalah MISI (Majalah Ilmu Ilmu Sastra Indonesia), jilid VII, No. 2. 1977, hlm. 35 - 54.

1979 Struktur Masyarakat Jawa Kuna pada jaman Mataram Hindu dan Majapahit, diterbitkan oleh Pusat Penelitian dan Studi Pedesaan \& Kawasan Universitas Gadjah Mada, Yogyakarta, th. 1979 (hlm. 1 - 92). 